\title{
Energy Led Refurbishment of Non-Domestic Buildings - Who Leads?
}

\author{
Megan E. Strachan ${ }^{*}$ and Phil Banfill \\ Heriot Watt University, Edinburgh, Scotland \\ *Megan E. Strachan. Tel: +44 1314514664,E-mail:mes8@hw.ac.uk
}

\begin{abstract}
Innovative and efficient refurbishment offers significant carbon savings and is a growing activity, driven by Government imposing energy or carbon related standards and policies upon building owners. Many businesses are becoming aware of the wider benefits of these improvements and therefore, their requirements as construction industry clients are changing. Built environment professionals need to recognize this change to remain competitive. This paper considers the question of whether there is a need for a re-alignment of disciplines within the industry to fulfill this growing role. A desk study, supported by structured interviews with users of large, non-domestic buildings and with industry professionals concluded that there is a role within the construction industry for a new built environment professional. A competence specification for this professional was defined and this paper outlines the skill set and knowledge base that this individual would require in order to deliver a truly innovative, comprehensive and compatible intervention set within an energy led refurbishment.
\end{abstract}

Keywords: Energy, Refurbishment, Client requirements

\section{Introduction}

The pressure placed on the built environment to reduce its $\mathrm{CO}_{2}$ emissions affects how clients treat their property portfolios. They expect construction professionals to take the lead in energy led refurbishment. The purpose of this paper is to explore the effectiveness of construction professionals, who already deal with a range of design-related issues, in leading such energy-led refurbishment. The main objective of this paper is to identify the competences required of built environment professionals able to lead this work, informed by both a desk study of their governing bodies' requirements and interviews with a small but representative group of professionals.

\section{Methodology}

A desk study surveyed the competency sets required by professional institutions. Structured interviews with 4 experienced professionals from building surveying, facilities management, project management and quantity surveying, and 3 clients (2 facilities managers and one energy manager) used open-ended questions to encourage discussion. The individuals were very experienced and the interviews were held in their offices, recorded and transcribed afterwards. This process allowed for reflection of the results and key points. .

\section{Interview Results}

Due to the number of interview questions - twenty-three questions for the construction industry professionals and sixteen for the industry clients - and the limitation on page numbers, the questions will not be presented. However, the questions and corresponding responses have been grouped into themes and it is these themes that are presented within 3.1 and 3.2 of this paper.

\subsection{Construction Industry Professionals}

\subsubsection{Refurbishment Context}

The interviewees generally agreed that the refurbishment process can vary widely, with works ranging from cosmetic to changing the function of an entire building. 


\subsubsection{Education and Training}

All the interviewees felt that their original education and training equipped them for their work, but their, possibly over ten years old, qualifications lack emphasis towards energy performance in buildings. Participant 1 stated that sustainability was addressed by their assessment of professional competence with the Royal Institute of Chartered Surveyors (RICS) but at insufficient depth for their day to day work. Those interviewees responsible for building design felt that they were under pressure to be aware of new technologies and materials as well as sustainability policies. Whereas those responsible for managing the design felt under less pressure, but need sufficient awareness to participate in design team discussions. The main pressure was coming from their clients' need for advice on sustainability issues. All were keen to undertake some re-training in the area of low carbon building design and operation, and stated that it would be beneficial if there were more Continuous Professional Development (CPD) events in this subject. The main barrier to undertaking re-training is finding the time to attend due to the pressures of their current role.

\subsubsection{Professional Governing Body’s Attitude}

The participants felt that their professional bodies had recently increased the focus on sustainability and its related issues, evidenced by an increased number of seminars and events on the subject. Participant 2 (engineering background) felt the Chartered Institution of Building Services Engineers (CIBSE) was pushing the 'Low Carbon Consultant' qualification forward, and he wished to pursue this as a credible path to specialising in low carbon design and operation of buildings. The others felt that their professional governing bodies were providing more guidance and seminars in the area but envisaged no change to their core competencies, from what they currently perceive, as an outline overview of sustainability.

\subsubsection{Companies' Attitudes}

All interviewees were aware of their companies' environmental policies and mission statements. Participant 3 remarked that information on the company's intranet brought the issues to their attention. Participant 4 described his company as forward thinking recognising the great commercial opportunity offered by becoming leaders in the field of sustainability, but did not apply the same practices to their own property portfolio. He believed that true leaders should improve their own properties as well as their clients'. Those needing to advise clients on technical aspects remarked that the message they got from their company was to present improving energy performance as a cost saving for the client, whereas those in a management role felt the company would never tell their clients what to do but rather base everything upon the client's requirements. Participant 4, involved in a range of project types within existing buildings, highlighted that within his company, there are several experts in the low carbon area because they have a keen interest in it or because they are part of the small teams the company creates to work on such projects, but their expertise was not transferred across all disciplines. Although, they felt they could always go to them to discuss issues or ask for advice. Overall the main conclusion drawn from the interviews was that the professionals are supported by their company if they choose to become more interested in sustainability, but are neither incentivised nor penalised if they do not.

\subsubsection{Clients' Attitudes}

Over the last five years many clients have run projects looking at lighting, cooling, controls etc, but this had slowed down with the recession. Conversely, since the Carbon Reduction Commitment Energy Efficiency Scheme (CRC) - a UK based mandatory emissions trading scheme for large energy users - was launched, clients are being forced to consider energy 
performance, and so far the professionals have found some clients to be wary of the scheme and try to avoid financial penalties, while others see it as an opportunity to show how energy conscious they are. Participant 3's comment "got to link it to cost to force change" referred to the need to link energy performance initiatives to financial incentives or penalties. They explained how many public sector clients have to achieve certain environmental performance standards, such as a BREEAM excellent rating, as a minimum in order to gain funding for their project. Other public sector bodies are appointing internal sustainability managers that the client must answer to and this pressure is then being passed onto the design team.

\subsubsection{Importance of Energy in Buildings}

All of the professionals concurred that energy performance of the building comes third behind health and safety and operational performance. However participant 1 did consider energy performance to form a major part of the operational considerations. In terms of the importance of energy performance of a building within a refurbishment scheme, the participants all agreed that capital cost comes first, although participant 4 stated that they try to communicate the benefits of lower operational costs due to energy saving interventions in the design and it was a matter of convincing clients to look beyond capital cost.

\subsubsection{Decision Making in Refurbishment}

The level of client involvement on projects depends upon the client type; the professionals explained that some clients are happy to provide basic requirements, e.g. function and seating capacities, while others want to be aware of all decisions made. They found that larger companies with internal design teams already have design guides in place to aid selection of interventions and it depends upon the client how closely the external consultants must follow these guides. The main point made by the professionals was that there is no standard process to refurbishment; the decisions are made based upon the design team's experience.

\subsubsection{Who Leads?}

All of the professionals stated that the mechanical and/or electrical engineer could be suited to taking the lead as they have an in depth understanding of the building's energy consumption but debated whether they would have the leadership competencies to do so, since experience suggests they are very focused upon their area and reluctant to comment more widely. Other professionals identified the building surveyor as a potential candidate due to their broader technical knowledge of buildings combined with their project management competence.

\subsection{Construction Industry Clients Interview Results}

\subsubsection{Company's Attitude}

All participants take a proactive approach to works on their property portfolio. Participant 5's internal team of designers creates design guides with energy performance requirements which external consultants follow. Some admitted that their buildings weren't at the leading edge of energy efficiency but they took responsibility for what they consumed and wanted to reduce that as far as possible. All had witnessed a change in their companies' attitudes, since the late nineties, driven by their clients wanting to see evidence of effective and efficient working practices. Participant 5's organisation has seen three pressures to become more focused upon sustainability and energy in buildings: firstly, their corporate responsibility reporting, a key driver, secondly, cost reduction to allow money saved on energy to be spent elsewhere, and thirdly, the CRC scheme (see 3.1.5), the introduction of which has driven their organisation to make changes such as accreditation of their building to the Carbon Trust standards. Initially their organisation's concerns were with the reputational aspect of the CRC Scheme and they 
were determined to be in the upper quartile of the public CRC league table alongside their industry competitors. However, this puts them at risk of future changes to the scheme.

\subsubsection{Company Strategy towards its Stock}

Participant 5's company has a proactive strategy towards improvement of their stock, with a continuous upgrade investment programme. Participant 6's company has guidelines for improvement of their portfolio with an energy performance charter, supported by an internal, Europe-wide forum to learn and share best practice. All participants have internal energy performance targets that work in line with their businesses. Participant 5's sustainability framework includes scrutiny of energy performance and puts the highest responsibility on a non-executive director at board level. All agreed that energy performance is high on their agenda. Participant 7's organisation's main driver for building selection is location quality. Energy efficiency comes third and if necessary they will include energy interventions such as fabric upgrades and controls within the fit out, but no major changes to key plant items.

\subsubsection{Whom do you consult?}

All explained that their organisations use both internal and external construction consultants, depending on the complexity and scale of the project at hand. Participant 5's company use an internal, technical compliance team to prepare and ensure compliance with their own design guides and the energy standards. They have a framework of external consultants who carry out and manage the design in accordance with these internally set standards. All of the participants stated that they have contractual relationships with external consultants and those contracts include energy performance related clauses. The most specific are with the repair and maintenance engineers, and participant 5 explained that the engineer must deliver year on year energy consumption reductions, the progress of which are discussed at monthly contract framework meetings. Participant 7 explained that they need to see evidence of the experience of these external professionals in energy performance improvements and how they have been innovative in past, similar projects. Participant 5 explained that clients are frustrated by the same initiatives and ideas/approaches to improvements in their properties coming from different consultants who are afraid to take risks with newer technologies/ideas. They look for openness and an ability to provide non-standard solutions, achieving the same conditions in their properties but without being restricted to standard, constant volume systems. They expect innovation from the industry experts.

\subsubsection{Your Optimum Professional}

The majority of the participants agreed that a mechanical and electrical consultant or engineer who has the competencies required to run or lead a project would be the ideal candidate because electricity is their largest outgoing. However they emphasised that they want someone who doesn't cover old ground, who can bring innovative ideas to the table and who can also build strong relationships with similarly innovative contractors and consultants. Participant 5's ideal professional is a controls engineer because focusing on controls does not require replacement of key plant and takes the control of the building to some extent out of the occupier's hands so they can be comfortable but not wasteful. However, they did state that they have not yet worked with a controls engineer who can work with and be intimately knowledgeable of the building, communicate their findings or ideas successfully and then be able to lead a project as well. 


\section{Discussion}

\subsection{Potential for a New Professional}

Both professionals and clients agreed that a mechanical or electrical engineer is associated most with energy usage in buildings and has the required detailed technical knowledge, and that they would have an in depth understanding of how the building consumes energy and the standards that must be met in non-domestic properties. However, they had never worked on a project where the mechanical or electrical engineer was the lead except where the building required an unusually high level of plant. One professional explained that, in their experience as a project manager, mechanical or electrical engineers tend to focus entirely upon their area of expertise. So the project manager felt that the response to any questions outside that area of expertise was “can't answer that question, we've done our bit”. In contrast, the clients wanted a leader to invoke innovative solutions across the property, that were not restricted to the plant room, and they hadn't so far found these leadership qualities in the mechanical or electrical engineers. Half of the professionals stated that the building surveyor may be suited to running an energy-led project due to their broad knowledge of building fabric and mechanical and electrical services as well as their ability to manage projects, and the building surveyor agreed that he would be wish to become more specialised in sustainability and energy in buildings. To lead such a project they would need training to become more familiar with both the legislative and policy side, alongside the technical interventions available. In summary both the professionals and clients interviewed saw the potential for a new service, potentially provided through existing professional routes. The professionals agreed that they all need to learn more in the area but a new or existing discipline needs to branch out into energy in buildings, existing disciplines expanding upon their original technical and management skills.

\subsection{Barriers to a New Professional}

Developing a new professional would alter the structure of the design team and require a client to accommodate an additional set of fees on projects where an entire design team is required. Participant 3 provided an example of where many of their clients are required, by their organisation, to achieve a minimum BREEAM rating [1], thus forcing them to consult a BREEAM advisor. However, due to the low fees available for this advisor, that individual is not used to their full potential, and is brought in for an initial workshop which often turns into a checkbox exercise, when they could be assessing and contributing to the design. In order to get the client to pay an additional set of fees on larger projects, they would need to be forced to employ that professional to ensure delivery of a particular credit or rating level. Participant 3 also remarked that the new professional would have to be accredited in some form to prove to the client that they are worth employing due to the new nature of the role.

\subsection{Drivers behind Energy-Led Refurbishment}

One of the major drivers behind energy improvements to client properties is government policies that force them to review and improve their energy performance through reputational and financial penalties. An interesting point to arise from the interviews was the need for careful design of these policies to ensure the desired results are achieved. For example one professional described how a public sector client was forced to meet the local council's renewable energy policy, by ensuring that their properties included a minimum level of energy supply through renewable technologies. There was debate over which heating system to implement and due to such a heavy focus on renewables, the decision was taken to install a cheaper (capital cost) electric heating system instead of a more energy efficient alternative and an air source heat pump was installed to meet the renewables requirement. As a result the building only achieved a C/D rating in its Energy Performance Certificate [2]. If the focus had 
been on the energy performance of the building as a whole then perhaps a B rating could have been achieved instead, resulting in a more energy efficient property. Following the interviews with owners of large, non-domestic portfolios, it was clear that the drive for refurbishment will also come from their own business needs. Some of those interviewed explained that in the current financial climate they are trying to reduce their property portfolio whilst ensuring growth in the core services they provide. This has resulted in less new build procurement and potentially decreasing the number of properties already in use by moving staff into the same buildings. This adaptation of existing buildings can only provide increased opportunity for energy efficient improvements.

\subsection{Construction Industry Views on Energy-Led Refurbishment}

One professional pointed out that some other professionals believe that the clients must ask for specific energy requirements during the project briefing and that it is not their job to tell the client what their requirements are. Other professionals disagree and see it as their job as the industry expert to inform the client of opportunities available to them if they consider the energy performance of their property. Some of the professionals explained that they feel it is inappropriate to put forward energy performance requirements to the client as they may not have the budget or may be running a separate energy related project. These barriers to pushing the focus onto energy performance need to be overcome if energy performance is to be taken seriously. In recent years, a sustainable building that does not waste energy is now being seen as a higher quality building. The United Kingdom's Green Building Council's Chairman states that “...good sustainability practice is good business practice - it's about producing better quality products, materials and buildings.” [3]. The triangle of cost, time and quality is still prominent in the industry and some professionals do not see efficient energy usage in buildings fitting into that shape. However the clients interviewed have shown that they are eager for the construction industry to take the lead and to show them true innovation.

\section{Optimum Built Environment Professional Competency Set}

Consideration of the competency sets laid down by the governing bodies of the construction industry professionals, combined with the outcome of the interviews held with built environment professionals and clients, leads to the following set of optimum competencies. This optimum competency set aims to define the core skills that a construction professional must fulfil in order to successfully promote and lead an energy-led refurbishment of a nondomestic property, one that will deliver a truly innovative, comprehensive and compatible intervention set. Table 1 presents the established built environment professions against the optimum competency set and shows which competencies each professional currently fulfils in accordance with their governing bodies' guidance. This is not the first time that the competency sets offered by built environment professionals have been critically examined in response to externally imposed changes. For example the development of project management into a clearly defined, accredited profession within the construction industry, codified a role that was previously considered as an additional competency of other construction professions. Accreditation of architects in building conservation is now established, and offers an alternative route to competence. It is evident that clients want to make their buildings more energy efficient but they are not getting what they need from the industry. They want innovative bespoke solutions that work for their buildings but to offer these the professional needs to be knowledgeable about new technologies and materials and to be able to present their benefits clearly. Current professionals admit that they do not know enough about energy in buildings so either a new profession is needed or the competences of existing professions must be overhauled. 
Table 1 Optimum Built Environment Professional Competency Set for Energy-led Refurbishment

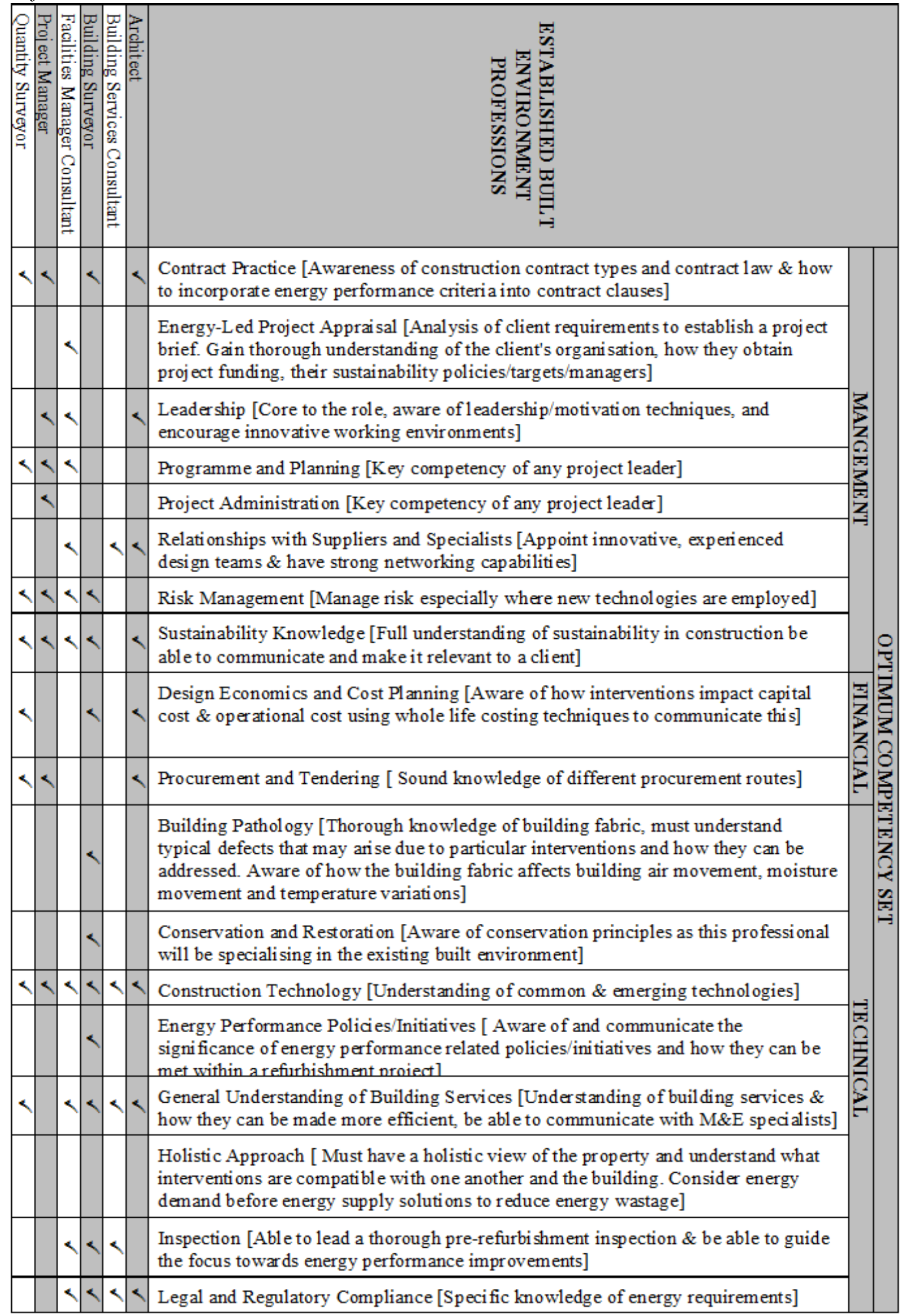




\section{Conclusion}

For the growing field of energy-led refurbishment, industry and clients desire competencies that are not currently offered by any existing professional group practising in the UK. This deficiency can be remedied either by developing a new profession, for which the desired competencies have been presented in this paper, in the same way as Construction Project Management was developed, or by establishing a recognizable specialized branch of an existing profession, in the same way as with architects or building surveyors who specialize in building conservation/preservation. Even though the study was carried out in the UK, the professions of those interviewed are internationally recognized. It would be interesting in a future study to compare the views expressed in other countries.

\section{References}

[1] BREEAM (2009) BREEAM Bespoke Single and Multiple Building Criteria [online]. Available from: http://www.breeam.org/page.jsp?id=181 (Accessed 21 November 2010)

[2] Directgov (2010) Energy Performance Certificates - What they are [online]. Available from: www.directgov.uk/en/HomeAndCommunity/BuyingAnd Selling Your Home /Energy performancecertificates/DG_177026 (Accessed 21 November 2010)

[3] King, P (2010) Good Sustainability Practice is Good Business Practice [online]. Available from: www.british-gypsum.com/literature/brochuresleaflets/csr report 2010 pdf.aspx (Accessed 21 November 2010)

[4] Royal Institute Of British Architects (2010) It's Useful to Know... [online]. Available from: www.arc-in-form.com/free/ItsUsefultoKnow.pdf (Accessed 21 November 2010)

[5] Royal Institute of Chartered Surveyors (2006a)Your Pathway to Qualifying in Building Surveying [online]. Available from:

www.rics.org/site/scripts/documents_info.aspx?documentID=390\&pageNumber=3 (Accessed 21 November 2010)

[6] Royal Institute of Chartered Surveyors (2006b)Your Pathway to Qualifying in Project Management [online]. Available from:

www.rics.org/site/scripts/documents_info.aspx?documentID=390\&pageNumber=3 (Accessed 21 November 2010)

[7] Royal Institute of Chartered Surveyors (2006b)Your Pathway to Qualifying in Quantity Surveying [online]. Available from:

www.rics.org/site/scripts/documents_info.aspx?documentID=390\&pageNumber=3 (Accessed 21 November 2010)

[8] Chartered Institution of Building Services Engineers (2009) Competence Criteria for MCIBSE [online]. Available from: www.cibse.org/pdfs/M2.pdf (Accessed 21 November 2010)

[9] British Institute of Facilities Management (2010) The BIFM Revised Competencies [online]. Available from: www.bifm.org.uk/bifm/membership/individualmembership/FMcompetences (Accessed 21 November 2010)

[10] Mansfield, J. (2001) 'What's in a name? Complexities in the definition of "refurbishment”, Property Management, vol.20, no.1, pp.22-30 